
Indonesia

\title{
MEDIA SOSIAL DAN PERDEBATAN BARU WACANA GENDER SERTA PENYELSAIANNYA DALAM PERPSEKTIF ISLAM
}

Ach Tijani *

IAIN Pontianak achtijani@gmail.com

- Received: 15 Nov 2019 •Accepted: 4 Des 2019 •Published online: 11 Des 2019

Abstract: Media sosial adalah ruang sosial digital baru bagi masyarakat dunia yang berisi berbagai macam perbincangan, termasuk perbincangan gender. Kajian ini akan mengulas perdebatan baru persoalan gender di media sosial. Kajian ini menggunakan analisa filosofis dan penyelesaian dalam perspektif Islam. Melalui analalisis filosofis, diketahui bahwa dalam media sosial terdapat problem toxic of masculinity dan over feminity yang melanggengkan problem gender dari ruang faktual ke ruang virtual. Islam memberikan tawaran yang sangat optimis agar tetap tidak beranjak dari media sosial dengan menggunakan tiga prinsip dasar yaitu, rational, emperical inquiry dan morality.

Keywords: Media Sosial, Gender, Maskulinitas, Feminitas

\section{A. PENDAHULUAN}

Media sosial adalah ruang baru digital yang kehadirannya diterima ramah oleh masyarakat dunia secara umum serta diterima sangat antusias oleh kaum muda secara khusus. Dalam ruang baru tersebut mendeskripsikan sebagian kehidupan faktual berupa bentuk komunikasi, negoisasi, konstruksi yang memuat gambaran dan ekspresi gender serta identitas seksualitas ${ }^{1}$. Secara implisit media sosial menjadi ruang lingkup baru dan membuka perdebatan baru mengenai persoalan gender. Salah satu pembuka perdebatan baru dalam media sosial sebagai bagian dari pertumbuhan komunikasi industri juga melahirkan bentuk kekerasan baru yang kerap mengancam kehidupan normal kaum perempuan. Berkaitan dengan kekerasan terhadap wanita yang bermula dari media tercatat sejumlah kekerasan yang pada ujungnya sampai dapat merenggut nyawa perempuan banyak dijumpai di berbagai negara. Di Bolivia tercatat kekerasan domestik menjadi tren kekerasan tertinggi

\footnotetext{
${ }^{*}$ Corresponding Ach Tijani, Email: achtijani @gmail.com

${ }^{1}$ Boyd, d. m.." Why youth social network sites: The role of networked publics in teenage social life". Dalam D. Buckingham (ed.), Youth, Identity, and Digital Media. Cambridge, MA: MIT Press 2008
} 


\section{Ach Tijani}

terhadap wanita yang disebabkan oleh media. Di Meksiko ribuan perempuan menjadi korban akibat dari feminisasi (feminicide) dalam bentuk pelemahan dan subordinasi kaum perempuan. Sampailah pada puncak jual beli perempuan (women trafficking) mencapai 80 persen dalam tiap tahunnya yang bermula dari penggunaan media 2 .

Di dalam ruang media sosial tersebut, perempuan seumpama korban yang baru lolos dari mulut harimau, kemudian masuk lagi ke mulut buaya. Media sosial tak ubahnya seperti ruang historisitas masa lalu mereka yang tertindas, berevolusi dalam ruang wajah baru dan cerita baru (new story) yang sama sakitnya dengan kondisi mereka di masa lalu. Bahkan, boleh jadi ruang baru tersebut akan sangat lebih kejam, karena media sosial begitu sangat terbuka dengan segala kesederhanaan aksesibilitasnya (accesibility). Gejala kekejaman baru tersebut begitu sangat kentara dalam performa penggunaan media sosial oleh anak-anak muda, dimana tubuh perempuan menjadi obyek perhatian (body-objectified) yang menggiring para perempuan terdesak untuk menampilkan sisi keseksian kewanitaan yang paling tinggi (hyper fiminine sexulised). Gambaran seksi tersebut menjadi konstruksi gambaran (image construction) yang menunjukkan kesempurnaan seorang perempuan menjadi perempuan yang sesungguhnya atas dasar kemauan para lelaki. Padahal gambaran tersebut adalah racun maskulinitas (toxic of masculinity) yang sejatinya telah menghabisi jati diri perempuan itu sendiri. Walau pada sisi yang lain fenomena tersebut juga mengikis jati diri pria, namun kiranya perempuan lebih tidak berdaya dibandingkan laki-laki ${ }^{3}$

Akibat dari fenomena tersebut di atas, terjadi perbincangan kategori cantik dan tampan, disuka dan tidak disukai (like and dislike) di media sosial dengan berbagai kreteria yang mengakomudir nilai, identitas, sikap dan sosio-kultural pada level makro dan mikro. Berikutnya akan berdampak sepenuhnya pada kehidupan pribadi para pengguna media sosial tersebut ${ }^{4}$. Disinilah peluang ekstensi penghargaan dan justifikasi mengenai keperempuanan (feminity) tidak hanya sekedar persoalan tubuh seksi, tetapi juga pada pilihan-pilihan pakaian, pilihan makanan, cara makan dan

\footnotetext{
${ }^{2}$ UN,; Observatorio Ciudadano Nacional del Feminicidio, 2011

3 Holloway, K. (2015, June). Toxic masculinity is killing men: the roots of male trauma. Salon. Available http://www.salon.com/2015/06/12/toxic_masculinity_is_killing_men_the_roots_of_male_trauma_ partner/

${ }^{4}$ Barat Dastjerdi N, Sayadi S. Relationship between Using Social Networks and Internet Addiction and Depression among Students.( Journal of Research in Behavioral Sciences. 10(5). 2013), h. 332-341
} 
bahkan pola keberagamaan akan mempengaruhi perempuan agar kemudian dapat diterima sebagai perempuan sejati di hadapan para lelaki ${ }^{5}$.

Media sosial sebenarnya tidak selalu dipahami sebagai konduktor subordinasi kaum perempuan di hadapan laki-laki, akan tetapi media sosial juga dapat berfungsi sebagai ruang untuk saling mempengaruhi relasi perempuan dan laki-laki. Media sosial dapat difungsikan untuk merepresentasikan diri sebagai bentuk reaksi dan kritik terhadap yang lain ${ }^{6}$. Namun di sisi yang lain media sosial berfungsi sebagai alat pencari perhatian ${ }^{7}$. Secara implisit seorang perempuan akan berhadapan dengan dua pilihan dilematis yaitu antara memegang harga diri (self esteem) atau memilih mendapatkan perhatian.

Berangkat dari data dan sejumlah argumentasi, tulisan ini hendak menguraikan dua pokok persoalan, pertama konstruk perdebatan gender apa yang telah terbentuk dari hadirnya media sosial sosial. Kemudian kedua, peluang yang dapat dimanfaatkan dari hadirnya media sosial pada persoalan gender sebagai sebuah tawaran dalam perspektif Islam.

\section{B. HASIL DAN PEMBAHASAN}

\section{Media Sosial; Ruang Negoisasi Maskulinitas dan Feminitas}

Media sosial merupakan satu aplikasi jejaring sosial yang mempertemukan jutaan pengguna internet saling berinteraksi dan berbagi informasi. Secara khusus medis sosial sengaja didesain layaknya kekhidupan sosial faktual, dimana yang satu dengan yang lainny dapat saling menyapa dan berkelompok di dalam lingkungan virtual $^{8}$. Melalui media sosial terdapat beberapa manfaat termasuk invasi kultural yang dapat dengan mudah diakses oleh para pengguna internet. Disitulah para pengguna internet juga akan berhadapan dengan apa yang boleh dan tidak boleh dalam perspektif nilai kepantasan yang berbeda antar satu tempat dengan tempat yang lain. Melaui jaringan internet, media sosial menjadi halaman kampung baru yang mencairkan segala pembatas nilai kepantasan, sehingga kadang para pengguna

\footnotetext{
${ }^{5}$ Ringrose, J., \& Rawlings, V.. Posthuman performativity, gender and "school bullying": Exploring the material-discursive intra-actions of skirts, hair, sluts, and poofs. (Confero: Essays on Education, Philosophy and Politics, 3(2), 2015)h. 1-37

${ }^{66}$ A. B. Heilbrun, Measurement of masculine and feminine sex role identities as independent dimensions, (Journal of consulting and clinical psychology, 44(2), 1976),h. 183.

7 K. Richer, Facebook. In Beginning iOS Social Games https://doi.org/10.1007/978-1-4302-4906113 , h. 245

${ }^{8}$ Memar S, Adlipour S, Khaksar F. Virtual social networks and identity crisis With Emphasis on Identity Crisis in Iran. (Social Studies and Research in Iranian. 2013; 4(1)), h. 155-176
} 


\section{Ach Tijani}

media sosial justru mendapatkan fungsi yang negatif dari hadirnya internet dan media sosial tersebut 9 .

Berikutnya, setiap orang dapat menambah perkawanan baru dan pertukaran pikiran baru yang kemudian akan saling mempengaruhi adanya perubahan dalam kehidupan ${ }^{10}$. Indetitas gender juga menjadi salah satu persoalan yang paling banyak dibicarakan dan saling menukar anatar pengguna media sosial. Mulai dari sekedar persoalan kelamis seksualitas, sampai pada posisional perempuan dan wanita di kehidupan sosial. Sehingga persoalan gender yang sesungguhnya dalam kehidupan virtual sama posisinya dengan kehidupan faktual, yaitu persoalan asumsi dan pemberlakuan individu dan kelompok terhadap posisi laki-laki dan perempuan di dalam berbagai aspek kehidupan ${ }^{11}$.

Media sosial seperti layaknya media yang lainnya tidak selalu merepresentasikan personal, tetapi juga merepresentasikan kelompok tertentu. Kecenderungan tersebut tidak dapat dielakkan, sehingga persoalan negoisasi posisi gender antar laki-laki dan perempuan yang termanifestasi dalam asumsi dan pandangan individu maupun kelompok selalu akan cenderung pada kelompok yang dominan. Disinilah kemudian muncul juga streotip terhadapa kaum perempuan yang dalam kancah kehidupan global posisi perempuan masih tidak dapat sepadan dengan posisi laki-laki. Berbagai media, termasuk media sosial, tubuh perempuan masih menjadi tubuh primadona untuk diekploitasi dalam kepentingan dagang. Misalnya, tubuh perempuan masih sangat laris untuk mempromosikan produk terntetu, di sisi yang lain perempuan juga dijadikan obyek seks untuk mendekorasi berbagai kepentingan ${ }^{12}$.

Ditegaskan dalam sebuah hasil penelitian, bahwa media sosial terus memperkuat sreotip terhdap perempuan. Secara umum dalam obrolan dan iklan, perempuan terus didudukkan sebagai obyek seks. Sehingga dari situ tubuh-tubuh perempuan betul-betul menjadi alat komersil untuk kepentingan yang labih besar. Produk-produk dagang pada umumnya masih sangat sering menggunakan potret perempuan sebagai penggugah selera calon pelanggannya. Oleh karena itu, antara kehidupan faktual dan virtual, media sosial masih menggambarkan hal yang sama

\footnotetext{
${ }^{9}$ Pelling EL, White KM. The Theory of Planned Behavior Applied to Young People's Use of Social Networking Websites. (Cyber Psychology \& Behavior. 2009; 12(6), h. 755-759

10 Ibid, h. 755-759

11 Sadock B Kaplan HI, Synopsis of psychiatry behavioral sciences/clinical psychiatry.(Philadelphia: Williams \& Wilkins Co 2007)

12 E Goffman, Gender Advertisements. (New York: Harper/Colophon,1979)

Jurnal Equalita, Volume (1), Issue (2), Desember 2019 
mengenai wacana mainstream gender yang masih berkutat pada stretip terhadap kaum perempuan ${ }^{13}$.

Hasil penelitian yang lain juga menunjukkan, bahwa obyektifikasi tubuh perempuan sebagai obyek seks telah mengakar kuat. Sebagaimana beberapa postingan kaum perempuan yang secara tidak sadar banyak memperlihatkan kemolekan tubuh, sementara kaum laki-laki lebih bervariatif. Kecenderungan tersebut tentu juga memiliki keterhubungan dengan dominasi iklan yang juga ditayangkan di media sosial yang memperlihatkan konstruk tbuh perempuan yang dibangun oleh kepentingan ekonomi dengan memperlihatkan keseksian perempuan. Sehingga dari situ, setiap perempuan seakan tidak menjadi perempuan lagi begitu tidak mampu menunjukkan kemolekan tubuhnya ${ }^{14}$.

Persoalan kemolekan tidak hanya berhenti pada eksploitasi tubuh perempuan untuk iklan dagang, tetapi justru sampai pada jual beli tubuh perempuan itu sendiri. Salah satu bisnis yang dapat dibilang sangat menguntungkan adalah eksploitasi brutal adalah jual beli perempuan (women traffiking) ${ }^{15}$. Jual beli yang dimaksudkan tidak sama dengan transaksi seks. Jual beli perempuan adalah penggunaan tubuh perempuan untuk memperkaya orang lain. Artinya, pekerja seks justru dianggap sebagai satu pilihan profesi yang wajar, sementara jual beli perempuan menyisakan kerugian pada kaum perempuan. Disini harus dibendakan mana seks sebagai sebuah profesi dan di area yang mana yang dimaksud dengan eksploitasi seks ${ }^{16}$.

Dalam suatu kasus dan perdebatan gender bahwa seks sebagai profesi tidak termasuk sebagai unsur yang mendegradasi kedudukan perempuan. Justru perempuan-perempuan Iran, Thailand dan beberapa dari negara lain yang memilih profesi seks tanpa ada rasa trauma, akan tetapi mereka hanya bertujuan untuk menjadi perempuan yang mandiri. Dari temuan ini menunjukkan bahwa pekerja seks itu sama sejajarnya dengan profesi lain, justru subordinasi perempuan para pekerja seks itu lahir, ketika pandangan sosial yang diskriminatif terhadap profesi seks tersebut. Pada sisi yang lain, pilihan profesi seks tersebut justru dijadikan

\footnotetext{
${ }^{13}$ Debastuti Dasgupta, Gender Portrayal in Age Social Networking Site (Amity Jurnal of Media \& Communication Studies, 2018).

${ }^{14}$ Ibid.

15 Stoecker, S. "Human trafficking: A new challenge for Russia and the United States" dalam: S. Stoecker and L. Shelley, eds. 2005. Human Traffic and Transnational Crime: Eurasian and American perspectives. (Oxford: Rowman \& Littlefield, 2005), h.13-28.

${ }^{16}$ Andrijasevic, R. Migration, agency and citizenship in sex trafficking. Hampshire, (UK: Palgrave
} Macmillan, 2010) 
kesempatan oleh orang-orang tertentu untuk mengeksploitasi ketidak berdayaan finansial para pemilih profesi seks untuk memperkaya diri. Kondisi ini makin menjauhkan pada fakta yang sebenarnya mengenai seluk beluk latar belakang dari hadirnya profesi pekerja seks, yang kemudian selalu dipandang hina secara sosial ${ }^{17}$.

Netizen atau warga media sosial secara umum memiliki pandangan yang sama dengan masyarakat faktual yang memandang rendah profesi seks. Di sisi yang lain justru memandang eksploitasi tubuh perempuan sebagai figur iklan adalah hal yang baik. Padahal jika mau ditelisik lebih jauh, eksploittasi dalam berbagai bentuknya selalau menyisakan kerugian pada pihak perempuan. Para pemilik modal tersebut telah mengurangi hak yang sebenarnya yang harus diterima perempuan yang telah menjual kemolekan tubuh mereka. Inilah kenapa kemudian bahwa eksploitasi itu sebenarnya yang telah mensubordinasi pihak perempuan, sementara profesi pekerja seks lebih manusiawi, sehingga dalam pandangan Barat seperti di Denmark banyak keluarga yang justru mensupport pilihan profesi pekerja seks tersebut sebagai bentuk tanggung jawab dari perempuan terhadap kahidupannya, anak-anaknya atau bahkan untuk keluarganya ${ }^{18}$.

Eksploitasi tubuh perempuan dengan menjual kenikmatan seks dan media memiliki sejarah cukup panjang. Jajakan seks komersil via media sudah dikenal masyarakat luas sejak abad ke-19. Disitulah memperlihatkan perempuan sebagai korban ${ }^{19}$. Fakta ini bersamaan dengan sejarah hegemoni maskulinitas di ruang media. Hal ini ditunjukkan dengan segala definisi terkait dengan perempuan yang selalu dikonstruk para lelaki ${ }^{20}$. Persoalan definisi tentang perempuan mempunyai dampak langsung terhadap perempuan, misalnya mengenai konsepsi cantik yang dikonstruk oleh pihak laki-laki akan menggiring setiap perempuan melakukan segala apapun yang diinginkan oleh laki-laki.

Hegemoni maskulinitas ini hadir dengan segala kelembutannya, merambat dari kehidupan yang sangat lokal hingga kemudian dapak mengkonstruk keperempuanan secara global. Dalam konteks lokal dimulai dari kehidupan keluarga, dimana secara

${ }^{17}$ Shahrokhi, S.,." Beyond "tragedy": A cultural critique of sex trafficking of young Iranian women". dalam: T. Zheng, ed.. Sex trafficking, human rights and social justice. (Oxon and New York: Routledge2010), pp.37-46.

18 Plumbech, S., 2010. "From Thailand with love: Transnational marriage migration in the global care economy. Dalam : dalam: T. Zheng, ed.. Sex trafficking, human rights and social justice. (Oxon and New York: Routledge2010), h.47-61

${ }^{19} \mathrm{~J}$ Doezema, Loose women or lost women? The re-emergence of the myth of white slavery in contemporary discoursesof trafficking in women. (Majalah Winter Issue 2000) h.23-50

${ }^{20}$ R. W, Connell,. Masculinities. (Berkeley: University of California Press, 1995)

Jurnal Equalita, Volume (1), Issue (2), Desember 2019 


\section{Ach Tijani}

umum anak perempuan lebih banyak mendapat perhatian perawatan dari perawatan tubuh hingga koleksi pakaian yang layak sehingga kemudian anak perempuan tadi dapat diakui secara sosial sebagai perempuan. Dalam skala regional dapat dilihat dari struktur keorganisasian yang seringkali menempatkan posisi perempuan pada beberapa aspek yang dianggap kurang strategis, sebagai sekretaris dan strukturstruktur lain yang didalamnya memungkinkan terjadinya eksploitasi keelokan tubuh perempuan. Dalam skala global, terdapat upaya-upaya penyeragaman nilai kepantasan berpakaian, biasanya nilai-nilai ini digandengkan dengan ideologiideologi besar seperti agama 21 .

Secara umum dalam perdebatan gender posisi perempuan di hadapan media masih dikatakan sangat lemah. Lemah dalam arti peran perempuan dalam pengelolaan media masih sangat minim. Media-media besar, termasuk media sosial peran perempuan sebagai pengelola juga masih sangat minim. Jikapun terdapat para perempuan yang berkecimpung, tetapi kehadiran perempuan masih tidak dapat menempati ruang yang strategis, sehingg segala konten yang ada dalam media secara tidak langsung banyak diarahkan oleh kaum laki-laki ${ }^{22}$.

Sejumlah analisis di atas menunjukkan bahwa kehadiran media sosial sebagai ruang baru di era digital bagi kaum perempuan masih sebagai tantangan ketimbang menjadi peluang. Perlu mendapatkan perhatian agar kehadiran perempuan di ruang media sosial mampu berdiri sejajar dengan para lelaki. Hal tersebut terjadi, karena persoalan perempuan dalam perdebatan gender di ruang faktual masih belum selesai sepenuhnya, sehingga stereotip di ruang faktual masih sangat kuat mengalir deras ke ruang digital.

\section{Islam Sebagai Solusi dan Peluang}

Merespon benang kusut perdebatan gender di ruang media sosial sepertinya Islam sebagai salah satu agama yang memiliki konsep keperempuanan perlu mengambil bagian untuk memberikan tawaran solusi. Dalam konstruk teologis, Islam secara tegas menjelaskan posisi laki-laki dan perempuan berdiris sejajar dalam hak dan kewajiban. Hal tersebut terlihat dari konsepsi reward dan punishment yang dijanjikan dalam teologi Islam tidak mengacu pada perbedaan status gender, tetapi

\footnotetext{
${ }^{21}$ C Beasley, C, Rethinking Hegemonic Masculinity in a Globalizing World. (Men and Masculinities, 11(1) 2008), h..86-103

${ }^{22}$ Lihat : http://www.consilium.europa.eu/uedocs/cms_data/docs/pressdata/en/lsa/137546. pdf. Dikases tahun 2013
} 


\section{Ach Tijani}

lebih peran, tanggung jawab yang diemban oleh masing-masing manusia, baik itu yang disandang oleh laki-laki maupun yang disandang oleh perempuan ${ }^{23}$.

Dalam konsepsi relasi laki-laki dan perempuan sejumlah ulama menempatkan perdebatan ini masuk dalam kategori teologis yang berkaitan langsung dengan inti predikat kesilaman yang disandang oleh seseorang. Seorang mu'min tidak dapat dikatakan beriman secara sempurna selagi belum mampu menempatan perempuan sebagai mitra sejajar dalam kehidupan. Term mitra sengaja dipilih sebagai term yang menunjukkan keseimbangan dan kesetraan tanpa menunjukan posisi struktural atas dan bawah. Konsepsi sederhana ini berimplikasi pada tataran kehidupan lainnya, disitulah kemudian segala sikap akan merepresentasikan keadailan bagi perempuan $^{24}$.

Secara rigid bentuk keadilan tersebut tercermin pada hak dan kewiban yang setara pada beberap bagian sebagai berikut ${ }^{25}$ :

1. Hak kemerdekaan.

Perempuan dalam Islam tidak hanya memiliki kebebasan, tetapi perempuan memiliki hak kemerdekaan. Term merdeka walau memiliki dimensi kesamaan dengan kebebasan, namun terdapat marka pembeda. Kebebasan cenderung tidak menunjukkan sisi rasionalitas, sementara kemerdekaan memiliki dimensi rasionalitas dan tanggung jawab, tidak hanya selesai persoalan tanggung jawab di dunia, tetapi Islam juga menempatkan tanggung jawab di hadapan Tuhan. Kemerdekaan ini tidak memiliki limit pada aspek tertentu, tetapi kemerdekaan yang menjangkau seluruh seluk beluk kehidupan perempauan. Secara khusus kemerdekaan itu juga melekat pada penggunaan hak miliknya, mulai dari harta sampai pada tubuh yang mereka miliki ${ }^{26}$

Hak kemerdekaan ini, barangkali menjadi hak asasi sebelum kemudian muncul hak-hak lainnya baik sebagai bagian dari kehidupan sosial atau perempuan sebagai individu. Tanpa ada hak kemerdekaan, maka tidak mungkin ada hak-hak lain yang akan melekat pada perempuan.

2. Hak seksualitas

Hak sesksualitas adalah hak asasi kemanusiaan yang melekat pada siapapun, laki-laki dan perempuan serta kecenderungan orientasi seks lainnya.

${ }^{23}$ M. al-Siba'i, al-Mar'a Bayn Fiqh Wal-Qonun, (Beirut :al-Maktab al-Islami, 1962) h.26

${ }^{24}$ Haifaa A. Jawad, The Right Of Women in Islam,( USA : ST. Martin's Press, 1998) h. 5

${ }^{25} \mathrm{Ibid}$, h. 7

${ }^{26}$ Anis Ahmad, Women and Social Justice (Pakistan : Institute of Policy Studies, 1991) h. 80 Jurnal Equalita, Volume (1), Issue (2), Desember 2019 
Perempuan dalam Islam memiliki hak tersebut, mulai dari pilihan menikah, tidak menikah dan menikah dengan hasil pilihan dan pertimbangan kedewasaannya. Semuanya ada di tangan pilihan perempuan itu sendiri, tanpa harus tunduk pada opini dan penggiringan pihak lain di luar dirinya, termasuk dari kaum laki-laki.

Persoalan seksualitas sejatinya tidak hanya persoalan seks semata, tetapi juga didalamnya melekat hak identitas. Karena di beberapa tempat seperti di Barat, perempuan memang memiliki hak seksualitas, akan tetapi akibat dari kepemilikan hak seksualitas justru pada saat menikah identitas seorang perempuan tereduksi dengan menambah identitas suaminya di belakang namanya. Keaslian dari identitas perempuan yang dimiliki perempuan Barat setelah terkonversi menjadi identitas properti yang dilekatkan kepada suami. Di dalam Islam tidak kenal pada perampasan identitas keperempuanan, sehingga perempuan yang menikah dalam Islam tidak berkonsekuensi harus menyatakan bahwa dirinya adalah milik suami. Namun yang melekat pada perempuan yang menikah adalah terdapat pada tanggung jawab yang melekat padanya.

Semua hak-hak yang berkaitan dengan seksualitas ini akarnya adalah hak spritulitas, berfikir dan berperasaan secara proporsional ${ }^{27}$. Sehingga pada tataran implementasi juga tidak kaku, karena Islam hanya menyediakan landasanlandasan pijakan universalitas, di sisi yang lain sangat memungkinkan untuk diterjemahkan dalam praktek yang beragam dalam kehidupan sosial umat muslim di seluruh dunia asal tidak keluar dari landasan esensial tersebut.

3. Hak dalam pendidikan.

Qur'an dan sunnah sebagai dasar dari agama Islam memberikan hak kepada laki dan perempuan dalam bidang pengetahuan. Hal ini tentunya terkait dengan pendidikan sebagai sebuah lembaga penghantar pada sebuah pengetahuan.Pendidikan disini tidak sekedar formalitas seperti sekolah. Makna pendidika yang lebih luas adalah $t a^{\prime} d i b$ yang artinya suatu upaya yang dilakukan secara berencana untuk membentuk manusia yang berkeadaban. Kemudian makna berikutnya ada tasqif yang artinya pembiasaan atau pembudayaan. Berkeadaban tidak cukup, tetapi harus sampai menjadi budaya, sehinga seorang muslim dalam bertindak dan mengamalkan ajaran Islam tidak seperti hanya

27 Jamal Badawi, “Women in Islam” dalam Khurshid Ahmed, in Islam: Its Meaning and Message (Leicester: The Islamic Foundation, 1980) h. 137 
menunaikan dan menyelesaikan kewajiban, akan tetapi lebih sebagai sebuah kebutuhan.

4. Hak dalam politik.

Sudah sejak lama Islam memberikan kesempatan kepada wanita untuk mengekspresikan dirinya serta menyumbangkan pemikirannya pada publik. Hak politik tidak selalu melulu persoalan semangat untuk merebut kekuasaan, tetapi lebih sebagai ruang akomudatif terhadap segala masukan untuk kemaslahatan bersama. Di dalam Islam setiap orang dianggap sebagai pemimpin tanpa memandang apakah dia laki-laki atau perempuan. Kullukum Ro'in wakullukum mas'ulum 'a Roiyyatih setiap kalian adalah pemimpin yang memiliki tanggung jawab atas semua yang menjadi tanggung jawabnya. Jadi hak politik sejatinya dalam Islam adalah tanggung jawab itu sendiri.

5. Hak warisan.

Sebagai seorang anak, perempuan punyak hak waris dari orang tuanya sebagaimana seorang laki-laki. Disitulah diatur dengan rinci harta waris seorang muslim yang telah meninggal untuk keluarga yang telah ditinggalkan. Persoalan pewarisan ini dikenal dengan ilmu faraid. Namun demikian, hasil ijtihad berupa Faraid ini bukanlah satu putusan yang final, akan tetapi terus berpeluang terbuka untuk terus dilakukan perbaikan atas prinsip keadilan.

6. Mempunyai hak penghormatan.

Islam menghormati perempuan dan laki-laki secara adil tanpa mebedabedakan. Penghormatan yang dimaksudkan adalah penghormatan yang tulus, berpijak pada ajaran normatif keislaman. Bentuk penghormatan ini dalam alQuran disebut dengan lita'arafu (saling mengenal). Saling mengenal artinya bentuk penghormatan tersebut adalah interlreasi subyektif dan obyektif yang berimbang. Penghormatan tidak karena melihat obyek, tetapi juga dari kamampuan dan kondisi subyek.

Enam hal tersebut di atas dirasa cukup relevan dengan perdebatan gender dan media sosial saat ini. Berikutnya barangkali perlu diuraikan mengenai perpektif Islam terhadap media sosial itu sendiri. Media sosial sejatinya bukan persoalan kehidupan yang baru, hanya sebagai peralihan dari pola kehidupan faktual pada kehidupan digital. Maka dalam perspektif Islam media sosial sebagaimana namanya hanya sebatas media dan bukanlah sebagai dunia baru yang harus benar-benar mengubur dunia lama. Artinya media sosial jangan sampai melupakan sepenuhnya nilai-nilai 
dasar yang ada dalam dunia faktual. Karena itu nilai-nilai keislaman dalam dunia faktual harus digiring masuk pada ruang digital ${ }^{28}$.

Tawaran di atas memang bukan hal yang mudah, tetapi memang perlu dimulai dari penguatan penguasaan dasar pemahaman keislaman yang matang. Dalam problem kehidupan faktual saja belum sepenuhnya tuntas, kini harus menghadapi realitas baru berupa media sosial di ruang digital, tentu menjadi beban yang tidak mudah untuk diselesaikan. Pengalaman-pengalaman di ruang faktual tentu menjadi pertimbangan rujukan yang tidak boleh ditinggalkan.

Nilai-nilai dasar komunikasi dalam Islam cukup menjadi dasar dalam memasuki ruang media sosial. Persoalan komunikasi dalam Islam sejatinya bukan hal yang baru, karena tradisi keislaman dimulai dari komunikasi. Nilai komunikasi yang dibagun oleh Islam berangkat dari kejujuran, hati yang jernih dan saling mengormati. Hal tersebut berangkat dari prinsip tauhid dan tanggung jawab. Sebagai figur sentral dalam etika komunikasi adalah Nabi Muhammad. Nabi Muhammad menggunakan dua tipe kemunikasi, yaitu tipe komunikasi lisan dan tulisan. Prinsip dasar itu diantaranya adalah, moralitas (akhlak), perdamaian, memberi maaf, toleran, kebebasan persamaan untuk saling menghormati dalam perbedaan termasuk perbendaan gender ${ }^{29}$.

Dalam perspektif Islam, media sosial adalah suatu perkembangan yang baik. Media sosial dapat membangun hubungan yang baik antar satu dengan yang lainnya, khususnya untuk kepentingan belajar. Bahkan kehadiran media sosial disimpulkan sebagai media komunikasi yang efektif dan efisien, sehingga dalam hal ini sangat selaras dengan nilai-nilai dasar keislaman yang menjunjung efektifitas dan efesiensi30.

Hal lain yang harus diperhatikan selain dasar nilai gender, pola komunikasi dan penerimaan media sosial oleh masyarakat muslim adalah sejumlah perbedaan pendapat internal dan eksternal mengenai persoalan politik dan ekonomi. Persoalan ini sejatinya yang banyak mengendalikan sebagian besar persoalan kehidupan

\footnotetext{
${ }^{28}$ G.W, Falah, 2005. "The Visual Representation of Muslim/Arab Women in DailyNewspapers in the United States”.dalam: Falah, G.W., Nagel, C.R. (Eds.), Geographies ofMuslim women: Gender, religion, and space. (Guilford Press, 2005) h. 300-321

${ }^{29}$ Ibrahim Abd El Fattah Khalil, The Islamic Perspective of Interpersonal Communnication, (Journal of Islamic Studies and Culture (6) 2, 2016), h 22-37

${ }^{30}$ Farah Sazilin Johari dkk, An Islamic Perspective of Social Network Sites Usability on Students' Academic Performance in Selected Higher EducationI Institution in Malaysia, (International Academic Research Journal of Business Technology 2(2), 2016), h. 157-164
} 


\section{Ach Tijani}

termasuk persoalan gender di ruang media sosial. Mengantisipasi opini yang bergulir dari dua kepentingan utam dunia tersebut, maka yang ditawarkan Islam adalah menyiapkan muslimah yang berpendidikan dan berpengatahuan tinggi ${ }^{31}$.

Kehadiran media sosial walau dalam permukaannya menampakan kegarangannya terhadap posisi perempuan, Islam tidak menyarankan untuk menjauhi media sosial. Bahkan di luar dari dugaan, media sosial itu sejatinya adalah ruang negoisasi yang cukup menjanjikan untuk mengembalikan nilai tawar perempuan yang proporsional di ruang sosial, baik faktual maupun virtual. Islam tidak memiliki persoalan dengan wacana subordinasi perempuan, akan tetapi Islam secara esensial justru memiliki nilai pandangan yang berkeadilan bagi kaum perempuan. Kemerdekaan menjadi kata kunci yang sulit didapat dari wacana gender yang lain, tidak sekedar perlawanan tetapi lebih tepatnya adalah tawaran yang sangat rasional sekaligus juga bertanggung jawab.

Islam disini tidak boleh dipandang sebagaimana biasanya hanya sebatas agama, tetapi memang harus diletakkan sebagai way of life. Merujuk pada Islam tidak sekedar hanya kembali dan meninggalkan yang lain, tetapi kembali untuk menyelesaikan persoalan. Agama harus benar-benar menjadi kanopi sakral yang mampu menyelesaikan benang kusut persoalan sosial. Agama tidak boleh dijadikan pembatas yang sakral dan profan, justru agama harus menjadi pengubung. Segala priku keagamaan, mulai dari pemahaman, aksi, lingkungan dan interaksi adalah sistem yang integratif anatara dunia kehidupan manusia dan Tuhan yang Maha Sakral ${ }^{32}$.

Karena itu persoalan gender di ruang media sosial tidak dapat hanya diserahkan pada perlawanan antar kelas sosial, tetapi juga harus diikuti dengan tawaran spritulitas-ideologis. Agama tidak dapat didefinisikan sebelah mata sebagai akibat reaksi sosial, tetapi justru dapat dibalik bahwa reaksi sosial itu adalah akibat dari pemahaman agama. Karena itu Habermas juga menyatakan bahwa prilaku keagamaan adalah satu upaya membahasakan Tuhan yang sakral menjadi tindakan yang profan. Upaya ini adalah suatu argumentasi agama menuju modernitas. Segala modernitas tidak boleh berhenti pada sakralitas semata, tetapi harus turun menjadi

\footnotetext{
${ }^{31}$ Priscilia Offenhauer, Women in Islamic Societies: A Selected Review of Social Scientific Literature, (Washington DC: Federal Reserac Division Library, 2005), h. 119-120

32 Bryan S, Turner, Religion and Social Theory, (London: Sage Publication, 1991), xii-xiv Jurnal Equalita, Volume (1), Issue (2), Desember 2019 


\section{Ach Tijani}

pemahaman yang rasional, sekaligus juga menurunkan dalam bentuk tindakan yang teruukur untuk sebuah penyelesaian persoalan 33 .

Kompatibilitas Islam dan modernitas ini meniscayakan pada penerimaan media sosial sebagai instrumen pengembangan dan pweujudan misi Islam. Sehingga apapun ancaman dari media sosial, Islam memandang tidak berbahaya selama nalar modernitas itu sendiri masih melekat pada Islam. Justru yang berbahaya ketika nalar modernitas itu telah hilang dari Islam, maka berikutnya ancaman media sosial yang menakutkan itu akan menjadi kenyataan.

\section{SIMPULAN}

Media sosial adalah dampak dari modernitas yang kian menemui puncaknya. Kehadirannya tidak dapat dielakkan dengan segala bentuk resikonya. Pada intinya semua terbangun atas dasar keluhuran untuk menyelesaikan persoalan kehidupan manusia. Namun belakangan kadang terjadi pembelotan, akibar dari pertumbuhan teknologi dan kesiapan pranata sosialnya yang tidak berimbang. Sehingga dalam hal ini media sosial dan relasi dengan persoalan gender dianggap wajah dan ancaman baru bagi kaum perempuan.

Pokok persoalan dalam perdebatan baru dalam konteks media sosial adalah adanya over feminity dan toxit of masculinity. Perempuan digiring menjadi lebih dari sekedar perempuan hingga kemudian melahirkan bentuk eksploitasi baru di media sosial. Merespon hal tersebut Islam menawarkan optimisme dengan menempatkan media sosial pada posisinya sebagai instrumen yang harus dimanfaatkan, di sisi lain setiap manusia juga digiring kembali pada posisinya sebagai user bukan obeyek yang terksploitasi. Ada dua optimisme yang dibangun oleh Islam. Pertama, kembali kepada pemahaman awal mengenai perempuan dan haknya dalam Islam yang terdiri ada enam nilai dasar yaitu; hak kemerdekaan, seksualitas, pendidikan, politik, warisan dan pengormatan. Kedua, memanfaat media sosial dengan menggunakan media sosial dengan lima nilai dasar etik yaitu; moralitas (akhlak), perdamaian, memberi maaf, toleran, kebebasan persamaan untuk saling menghormati.

Kesimpulan tersebut dapat digambarkan dalam bagan sebagai berikut:

\footnotetext{
${ }^{33}$ Jurgen Habermas, Rationality Essay on Reason God and Modernity, (UK: Oxford, 2002), h. 1-5
} 


\begin{tabular}{|l|l|l|}
\hline \multicolumn{1}{|c|}{ Modernity } & \multicolumn{1}{|c|}{$\begin{array}{c}\text { Modernity's impact on } \\
\text { gender discourse }\end{array}$} & \multicolumn{1}{c|}{$\begin{array}{c}\text { Respons of Islamic } \\
\text { Perspective }\end{array}$} \\
\hline $\begin{array}{l}\text { Rational and Empirical } \\
\text { Inquiry }\end{array}$ & $\begin{array}{l}\text { Knowledge and Technology } \\
\text { many digital aplications } \\
\text { Gender's Problem } \\
\text { spirit } \\
\text { over feminity and toxic of to modernity's } \\
\text { masculinity }\end{array}$ & $\begin{array}{l}\text { Solve the problem with } \\
\text { Rational and Empircal } \\
\text { Iquiry and morality }\end{array}$ \\
$\begin{array}{l}\text { Breakdown of linguistifies } \\
\text { the sacred to profan } \\
\text { contect }\end{array}$ \\
\hline
\end{tabular}

Secara sederhana problem gender di ruang media sosial ini harus dihadapi dengan optimis dengan kembali memilih penyelesain nalar modern, karena media sosial itu sendiri dan berbagai problemnya adalah produk dari mdernitas.

\section{DAFTAR PUSTAKA}

Adlipour S, Memar S,2013. Virtual social networks and identity crisis With Emphasis on Identity Crisis in Iran. Social Studies and Research in Iranian. 4(1)

Andrijasevic, R. 2010. Migration, agency and citizenship in sex trafficking. Hampshire, UK: Palgrave Macmillan

Ahmad, Anis. 1991. Women and Social Justice Pakistan : Institute of Policy Studies

Ahmed, Khurshid. 1980 in Islam: Its Meaning and Message, Leicester: The Islamic Foundation

al-Siba'i, M. 1962, al-Mar'a Bayn Fiqh Wal-Qonun, Beirut :al-Maktab al-Islami

Buckingham, D. 2008 (ed.), Youth, Identity, and Digital Media. Cambridge, MA: MIT Press

Beasley,C, C. 2008. Rethinking Hegemonic Masculinity in a Globalizing World. Men and Masculinities, 11(1)

Connell, R. W, 1995. Masculinities. Berkeley: University of California Press

Doezema, J. 2000. Loose women or lost women? The re-emergence of the myth of white slavery in contemporary discoursesof trafficking in women. Majalah Winter Issue

Dasgupta ,Debastuti. 2018. Gender Portrayal in Age Social Networking Site, Amity Jurnal of Media \& Communication Studies.

Falah, G.W., Nagel, C.R. (Eds.). 2005., Geographies ofMuslim women: Gender, religion, and space. Guilford Press 
Goffman E. 1979, Gender Advertisements. New York: Harper/Colophon

Habermas, Jurgen. 2002. Rationality Essay on Reason God and Modernity, UK: Oxford

Holloway, K. (2015, June). Toxic masculinity is killing men: the roots of male trauma. Salon. Available at: http://www.salon.com/2015/06/12/toxic_masculinity_is_killing_men_the_r oots of male trauma partner/

Heilbrun, A. B. 1976, Measurement of masculine and feminine sex role identities as independent dimensions, Journal of consulting and clinical psychology, 44(2).

Jawad, Haifaa A. 1998, The Right Of Women in Islam, USA : ST. Martin's Press

Johari, Farah Sazilin dkk. 2016. An Islamic Perspective of Social Network Sites Usability on Students' Academic Performance in Selected Higher EducationI Institution in Malaysia, International Academic Research Journal of Business Technology 2(2)

Kaplan, Sadock B HI. 2007., Synopsis of psychiatry behavioral sciences/clinical psychiatry. Philadelphia: Williams \& Wilkins Co

Khalil, Ibrahim Abd El Fattah.2016, The Islamic Perspective of Interpersonal Communnication, Journal of Islamic Studies and Culture (6) 2

Offenhauer, Priscilia. 2005. Women in Islamic Societies: A Selected Review of Social Scientific Literature, Washington DC: Federal Reserac Division Library

Pelling EL, White KM 2009.. The Theory of Planned Behavior Applied to Young People's Use of Social Networking Websites. Cyber Psychology \& Behavior. 2009; 12(6)

Ringrose, J., \& Rawlings, V.2015. Posthuman performativity, gender and "school bullying": Exploring the material-discursive intra-actions of skirts, hair, sluts, and poofs. Confero: Essays on Education, Philosophy and Politics, 3(2)

Richer, K.2019. Facebook. In Beginning iOS Social Games https://doi.org/10.1007/978-1-4302-4906-1 13

Sayadi S, Barat Dastjerdi N,. 2013, Relationship between Using Social Networks and Internet Addiction and Depression among Students. Journal of Research in Behavioral Sciences. 10(5)

Stoecker, S. and L. Shelley, eds. 2005. Human Traffic and Transnational Crime: Eurasian and American perspectives. Oxford: Rowman \& Littlefield.

Turner, Bryan S. 1991 , Religion and Social Theory, London: Sage Publication UN 2011. Observatorio Ciudadano Nacional del Feminicidio, UNESCO

Zheng, T. (ed) 2010. Sex trafficking, human rights and social justice. Oxon and New York: Routledg 
Ach Tijani

http://www.consilium.europa.eu/uedocs/cms_data/docs/pressdata/en/lsa/1375 46.pdf. Dikases tahun 2013 